Letras, Lima. 1977-79. (Nos. 86-87), 47-60.

\title{
Lo Social y lo Religioso en Indole de Clorinda Matto de Turner
}

\author{
ANTONIO CORNEJO POLAR
}

El éxito alcanzado por Aves sin nido (1889), debió alentar a Clorinda Matto de Turner a continuar su producción novelística insistiendo en algunos aspectos de la primera obra, especialmente en la representación del espacio andino y en el cuestionamiento del mal clero, e insistiendo, al mismo tiempo, en un similar sistema de narración, enriquecido ahora con ciertos aportes del naturalismo (1). Es muy curioso, sin embargo, que Indole (2) desplace hacia un segundo plano, claramente accesorio, la problemática indígena, tan visible en Aves sin nido, precisamente en una novela que vuelve a presentar.al lector la vida en la sierra peruana. Tal vez intentó concentrar la fuerza de su enjuiciamiento en el sacerdocio envilecido por los malos curas y en los peligros de una falsal religiosidad, respondiendo así, con un nuevo y más incisivo ataque, a la dureza y fanatismo con que la Iglesia había recibido su primera novela (3). Sea de ello lo que fuere, lo cierto es que Indole perdió vigencia conforme el problema religioso se diluyó

(1) Un estudio del sistema narrativo empleado por Clorinda Matto puede encontrarse en: Antonio Cornejo Polar: "Para una imagen de la novela peruana del siglo XIX: Clorinda Matto de Turner", en Escritura, II, 3, Caracas, enero-junio 1977.

(2) Clorinda Matto de Turner: Indole (Novela Peruana), Lima, Tipo-Litografía Bacigalupi, 1891. Todas las citas corresponden a la única reedición de esta novela: Lima, Instituto Nacional de Cultura, 1974. El prólogo que aparece en esta edición puede entenderse como una primera versión del presente estudio.

(3) Así lo plantea Francisco Carrillo en Clorinda Matto de Turner y su indigenismo literario, Lima, Biblioteca Universitaria, 1967, p. 36. En este libro y en el de Alberto Tauro (Clorinda Matto de Turner y la novela indigenista, Lima, Universidad Nacional Mayor de San Marcos, 1976) pueden encontrarse otras referencias acerca de los conflictos de la Matto con la Iglesia. 
en la conciencia nacional (4), mientras que Aves sin nido, precisamente porque enfocó la cuestión indígena, ciertamente más importante y de mayor trascendencia social, continuó viva en la historia de la novela hispanoamericana.

\section{La bimembración del sistema narrativo}

Como todas las novelas de Clorinda Matto, Indole busca la obtención de dos objetivos no necesariamente coincidentes: por una parte, intenta la demostración de algunas tesis; por otra, pretende la representación de los rasgos que tipifican una realidad determinada. En este plano el dicurso narrativo cumple las dos funciones presentes ya en Aves sin nido, las de mostrar y enjuiciar la realidad, y añade la función explicativa, de filiación positivista, que apenas se podía vislumbrar en la novela anterior (5). Indole pretende cohesionar tesis y representación, confiriendo encarnación regional a algunos planteamientos abstractos, universales si se quiere, pero en general sólo logra yuxtaponer el tratamiento de uno y otro, alternándolos con cierto sentido del ritmo narrativo. La estructura básica de la novela obedece, pues, a esta duplicidad: el afán demostrativo, en referencia a la probanza de las tesis, comparte el espacio de la novela con el proceso de representación, alusivo éste, con sus funciones de mostración, juicio y explicación, a una realidad peculiar hasta lo pintoresco, la realidad de los pequeños villorrios y de las extensas haciendas de la sierra peruana.

En el plano de la rcpresentación Indole realiza en buena parte el modelo de la prosácostumbrista y de la novela realista de la época, en cuanto se esfuerza por of recer una imagen valorativa de sus referentes. Se trata, entonces, de una visión que engloba la mostración y el.juicio-juicio que puede ser sólo circunstancial o propio, más bien, de un sistema formalizado de valores. De esta suerte el lector recibe información sobre el objeto representado, que en este caso es frecuentemente pintoresco; sobre el valor o desvalor que se le asigna, a través de juicios expresos o de evaluaciones tácitas, que a veces sólo se coli-. gen de la tonalidad estilística del fragmento; e indirectamente, y no en todas las veces, sobre el sistema axiológico que en último término explica la selección del objeto y su juzgamiento concreto.

Ciertamente esta modalidad tradicional es la que mejor se em-

(4) En 1906 el entonces agnóstico José de la Riva Agüero señalaba enfáticamente que en el Perú no había Iucha religiosa pues el catolicismo es ya un "enemigo imaginario". Cf.: César Pacheco: "Unamuno y Riva Agüero: un diálogo desconocido", en: Apuntes, IV, 7, Lima, 1977. La carta citada es de 15 de diciembre de 1906, p. 153.

(5) Sobre Aves sin nido pueden leerse mis estudios: “Aves sin nido: indios 'notables' y forasteros", en: La novela peruana: siete estudios, Lima, Horizonte, 1977, y el "Prologo" a la edición cubana de esta novela: La Habana, Casa de las Américas, 1974. 
plea en Indole; sin embargo, la aparición de la "observación fisiológicomoral" como actitud narrativa, de procedencia naturalista, tiene mayor significado e importa más para el proceso histórico de la novela peruana, aunque en su uso se evidencie poca destreza. Se trata en una primera instancia de un voluntarioso esfuerzo por detectar la naturaleza psicofísica del comportamiento humano, en relación casi siempre con determinado medio ambiente, y por explicar sus caracteres y devenir en términos de objetividad científica. La observación de situaciones concretas, descritas con cierta minucia, se proyecta hacia un nivel explicativo que da razón "científica" de los mecanismos puestos en juego. En el fondo se trata de la aplicación a casos específicos de un conocimiento científico previo e incuestionable: "la observación fisiológico-moral ha demostrado ya lo suficiente que en estos casos el mayor esfuerzo empleado para extinguir la fuerza de la pasión es inútil" (p. 97, subrayado nuestro), aunque con mucha frecuencia, como puede desprenderse de la cita anterior, el sistema parece haber sido también el de seleccionar algunas situaciones que puedan servir casi a manera de ejemplo a ciertos principios científicos cuya validez se quiere enfatizar. La pareja mostración-juicio cambia su segundo término; ahora, al menos en un primer momento, no se trata de juzgar sino de explicar, y explicar en el orden de la validez científica. El juicio se demora y reaparece sólo en una segunda instancia: la observación del narrador es "fisiológica", sí, pero también "moral".

La "fisiología" que emplea el narrador es elemental y no siempre resulta coherente consigo mismo y menos con otros factores de la visión del mundo implicada en la novela. Se insiste reiteradamente en las correlaciones psicosomáticas, tanto en los retratos de los personajes ("la constitución "nerviosa del señor Peñas incrustada en su físico grotesco revelaba (...) el hombre nacido para la lucha material de la vida en la faena de los sentidos" - p. 102), cuanto en su proceder, de suerte que las reacciones físicas que contempla el observador remiten directamente al ánimo de la persona observada ("don Valentín desdobló el pliego arrugado (...) con él entre las manos comenzó a dar paseos por la habitación, con la actitud del que forja un plan en la mente. De improviso (...) se contrajeron sus labios plegados por la seca sonrisa que provoca la ejecución de una venganza" -p. 246). A veces los planteamientos de esta índole son notablemente ingenuos ("el momento fisiológico de la mujer que enamora con el supremo de los amores es aquel en que acabó de llorar y quedan sobre su rostro huellas húmedas del dolor" -p. 109), pero en todo caso forman una serie ininterrumpida a lo largo de todo el relato y hasta enriquecen considerablemente el arsenal metafórico del narrador ("una idea fija en su mente como un dolor neurálgico", por ejemplo -p. 96). Finalmente se llega a afirmar incidentalmente que la forma del cerebro "determina, ante la ciencia fisiológica, los talentos humanos y hasta la índole 
de los individuos" (p. 245), con lo que aparece una concepción crudamente materialista que choca con el idealismo romántico que impregna otros sectores de la novela, según se verá más adelante.

\section{Una nueva versión del mundo andino}

En Aves sin nido, el mundo andino aparece habitado por tres estratos bien diferenciados: indios, "notables" y forasteros. La composición social de los espacios que representa Indole, el pequeño pueblo de Rosalina y la hacienda Palomares, es distinta: por lo pronto, el estrato indio es apenas una vaga presencia en el trasfondo y el grupo forastero no tienen ninguna importancia; en cambio, aparece el grupo mestizo y los "notables" vuelven a ocupar el lugar de preeminencia que les correspondería en la primera novela si no actuara en ella la familia Marín (8).

De esta manera Indole bimembra la dimensión social del mundo representado: de un lado aparece la historia de las familias de don Antonio y don Valentín, que integra conflictivamente el cura Peñas; de otro, la historia de Ildefonso y Ziska, ciertamente menos importante que la primera. En el estrato más alto se contempla la vida, costumbres y conflictos de las familias "notables" y se desarrolla dinámicamente, en tono serio y dramático, la problemática central del texto; en el otro estrato, en cambio, aparecen los personajes mestizos y se procesa con humor ligero un acontecimiento no conflictivo. El vínculo narativo que los une es simplemente circunstancial (Ildefonso es sirviente de don Valentín y será apadrinado por don Antonio en su matrimonio con Ziska) y su sistema expresivo obedece a una norma elemental de alternancia no simétricalli Converso"

Don Antonio y don Valentín no tienen la misma situación que los "notables" de Kíllac, en Aves sin nido. Aunque ocupan un lugar importante en la sociedad de Rosalinda, como lo demuestra la deferencia con que los trata el cura Peñas, ninguno de los dos ejerce funciones gubernamentales y ambos tienen problemas económicos. Más que "notables" son vecinos ricos, con eventuales problemas de dinero, que desarrollan su actividad en el comercio de cierta envergadura y en la explotación de una gran hacienda (7). En ningún caso la no-

(6) Cf. ios estudios mencionados en la nota 5 .

(7) "Don Antonio López (...) estaba dedicado a la explotación de la cascarilla y el retorno de Europa en mercaderias de fácil acomodo en el interior del Perú, como bayetas de Castilla, lampas de aporque, panas de colores finos, espejuelos y esmaltes de combinación" (p. 36). De la hacienda Palomares, propiedad de Valentin Cienfuegos, se dice que "tenia gran nombradía en todo el departamento de Marañón, primero porque producía maiz blanco de tamaño sorprendente, tanto que disfruta de la golleria de haber obtenido medalla de oro en varias ex. posiciones extranjeras; segundo, porque sus frutillas son de notoria estimación por sabor, color y tamaño" (p. 41). 
vèla explica el por qué de la crisis económicà por la que atrảviesan y hay muy vagas referencias a las razones que llevan a don Valentín a acuñar dinero falso, comprometiendo en este delito a don Antonio. Supuesto que los negocios de ambos son lucrativos y que no se mencionan motivos específicos para la crisis que afecta a los dos, hay que convenir que la novela, sin aludir a ello de manera expresa, abarca un período de depresión en la economía andina. Como en el caso de Aves sin nido, en Indole hay un manifiesto descuido en la representación de la base económica de la sociedad.

La oposición que la novela construye entre las familias de Antonio y Valentín es básicamente moral: Antonio y Eulalia son personajes débiles, pero poseedores de "buena índole", mientras que Valentín y Asunción tienen una caracterización uniformemente negativa. $\mathrm{La}$ novela relata los distintos momentos del conflicto entre ambas familias, desde la caracterización estática de lo que los personajes han sido antes del tiempo novelado y la progresiva contaminación de los seres de "buena índole" por los vicios y defectos de los otros, hasta el triunfo final de la virtud. Este proceso se desdobla simétricamente: la honradez de Antonio ("primogénito de una familia que, en cien años de sucesión ininterrumpida en el Perú, fue el dechado de la honradez y las virtudes" - p. 115) se contrapone a la deshonestidad y villanía de Valentín (que no puede ocultar "una sonrisa verdaderamente satánica"), de la misma manera que la religiosidad auténtica y la dulzura de Eulalia ("angel de ternura y amor" - p. 115) se enfrenta a la beatería y acrimonia de Asunción ("verdadera hidra que se baña todos los días en agua bendita" - $p, 25)$.

El segundo estrato, el de $\mathrm{Ql}$ gente humilde, $\mathrm{Ses}$ muy simple. $\mathrm{Na}$ rra los afortunados amores Pdeclldefonso y Ziska - mestizos ambos-, simpático y ladino aquél, lozana e ingenua ésta (8). Un despreocupado tono bucólico, ameno y sonriente, enmarca la historia de sus simples sentimientos. Su desarrollo funciona distensivamente con respecto al acontecimiento principal; y en casos aislados, pero significativos, uno y otro nivel se vinculan en contrapunto. El espontáneo y dulce júbilo de los novios, durante la pintoresca ceremonia de su matrimonio, contrasta severamente con los oscuros conflictos que viven, en ese mismo momento, las familias importantes. Parecería quererse mostrar la saludable naturalidad de las pasiones puras, y de los seres capaces de vivirlas, en contradicción con los mezquinos dobleces y trampas de quienes, como Valentín, Asunción o el cuña Peñas, sólo obedecen a pasiones degradadas.

Aunque secundario, el relato de los amores de Ildefonso y Ziska lleva sobre sí buena parte de la función representativa del texto en relación a las costumbres serranas, enfocadas ahora, a la inversa de lo

(8) Ildefonso es hijo de "un caballero llegado a la villa con bastón de mando" (p. 42). 
que sucede en Aves sin nido, con manifiesta cordialidad. El mundo de los mestizos es un mundo realmente feliz y puede desarrollarse sin la interferencia, y más bien con el patrocinio, de las familias más encumbradas. Se trata, pues, de una visión bucólica, en nada problemática, de este sector de la vida andina.

El estrato indio no aparece más que en un segundo y muy difuso plano; sin embargo, cuando ocupa la atención del narrador, siempre de manera incidental, vuelve a mostrarse la terrible imagen que era propia de Aves sin nido: "el indio envuelto en la noche de la ignorancia, no sabe leer ni entiende el castellano, supersticioso y oprimido" (pp. 98-99), como también se aprecia en el episodio en que el Cura Peñas explota miserablemente a una india que viene a pedir sepultura para un familiar que acaba de morir (vid. I, XIX). La denuncia de la explotación y vejámenes que sufre el pueblo indio es, con todo, incomparablemente menos fuerte que en Aves sin nido, tanto que en una ocasión la desoladora presencia del pongo sólo sirve para un inciso romántico que casi nada tiene que ver con la energía que, en este campo, lucía Aves sin nido:

..pongo de la casa, fiel como el perro para el amo, fuerte para la vigilia como la lechuza, parco para la comida como criado con el uso de la coca, a veces abyecto por la opresión en que ha caído su raza, pero ardiente para el amor, porque en su naturaleza prevalece aquel instinto de la primitiva poesía peruana, que llora en el jay! de la quena, perdida en los pajonales de la sierra la opulencia del trono destruido en Cajamarca, y los brazos de la mujer adorada que rodearon el cuello decun extraño ( $p .38$ ).

Pero lo que distingue más a Indole de Aves sin nido, en el campo de la representación de la realidad social, es la ausencia del grupo de los forasteros. Al faltar éstos no hay el elemento comparativo que fundamenta el aparato axiológico de la primera novela y la visión de la vida andina resulta así bastante menos crítica. Eludido el problema indígena, afirmada la eglógica felicidad de los mestizos y procesada la oposición entre los vecinos ricos como una oposición solamente moral, Indole es una novela - en este aspecto- de muy escasa fuerza enjuiciadora. Ciertamente aparecen nuevamente algunas críticas a la vida provinciana ("estéril y triste" -p. 73) y los protagonistas piensan frecuentemente en abandonar Rosalinda para vivir en Lima, que otra vez recibe un elogio desmedido, pero en todo caso Rosalinda y Palomares son espacios casi paradisíacos en relación al sombrío Kíllac de Aves sin nido (9).

(9) De hecho en Rosalinda parecería no haber más problemas que los suscitados por el cura Peñas. La crisis económica de Valentín y Ántonio es vista siempre como una situación eventual. 
Es importante observar que el enjuiciamiento de la vida provinciana corre a cargo, en Indole, de los vecinos poderosos. Mientras que en Aves sin nido los "notables" levantan una cerrada defensa de sus costumbres y están dispuestos hasta a matar por conservarlas, en la segunda novela son los propios vecinos, don Antonio y don Valentín, quienes condenan las limitaciones de la sociedad en que viven. El criterio que emplean para sus críticas es, en este sentido, mucho más individual que el que aparece en Aves $\sin$ nido. Por lo pronto no hay referencias directas a la injusticia y a la inmoralidad, que en todo caso tendrían que procesarse en términos autocríticos, si no, más bien, a las escasas posibilidades de desarrollo personal que brinda la vida provinciana. Sometidos a la opresión de un horizonte pequeñísimo, los vecinos imaginan la felicidad casi siempre como una fuga de esa realidad agobiante: don Valentín en términos de placer y ganancia económica (vid. p. 73), don Antonio, personaje de "buena índole" al fin y al cabo, en términos de tranquilidad, perfeccionamiento moral y ambiente civilizado. Dice:

- Mi viaje es un hecho. Viviré contento allá [en Lima] donde se rinde culto al trabajo, donde uno puede confundirse con cientos de personas, con garantías para el hogar, y sin que la vanidad y las exigencias sociales me empujen al camino de la estafa (p. 243).

Puede decirse, entonces, que la condena de la vida provinciana está procesada en buena parte desde la perspectiva de los vecinos insatisfechos -y tal vez por esto sea menos punzante que en Aves sin nido, donde el juicio emana de los forasteros. Los otros dos estratos sociales que Indole representa, él de los mestizos e indios, no expresan juicio alguno: algunos parecen adecuarse bien a la realidad, y ser felices en ella, como Ildefonso y Ziska, mientras que otros, los indios, atrapados sustancialmente por un contorno de injusticia y explotación carecen de toda otra posibilidad que no sea la de sufrir y resignarse.

\section{Contra el celibato y la confesión}

El cura Peñas es el verdadero motor narrativo de Indole. Ligado a doña Asunción por vínculos de confesión y "paternidad espiritual", que implican el total vasallaje de la mujer ("dominada por el misticismo, que ciega y embrutece, morirá antes que delatar a su confesor" p. 242), el cura Peñas pretende establecer igual reación con doña Eulalia, y lo logra en cierto modo. Pero en este caso se trata de una obsesión sexual, muy pronto explicitada en el relato, que quiere realizarse al amparo de los ritos religiosos y de la ambigua relación entre confesor y penitente. Peñas utiliza su condición sacerdotal para acosar psicológicamente primero y físicamente después, a la esposa de don 
Antonio, llegando a emplear el más burdo chantaje para cumplir sus fines. A punto de ser vencida, Eulalia se salva con el "auxilio [de] una fuerza misteriosa como la impulsión de la índole de la persona nacida para el bien" (p. 194). De esta suerte "la serpiente de la seducción quedó enredada en las redes tejidas por la índole superior de la mujer, y no se mancharon las cisnerianas plumas de la paloma entre las garras del sucio milano" (p. 255).

La historia del cura Peñas, algunos de cuyos episodios están descritos con notable acritud (vid. I, XVIII; II, I), da ingreso en la novela al tema religioso. Como en Aves sin nido se proclama insistentemente la adhesión al "cristianismo puro" y a él se remite una larga serie de reflexiones religiosas y morales que tienen la función de fijar la posición del narrador. Sin embargo, frente a esta visión positiva de la religión, se construye un plano abiertamente antitético en el que se remarcan, insistentemente también, los vicios de la religión falsificada. Esta perspectiva crítica enfoca aspectos de muy distinta naturaleza e importancia: desde la "manía del rezo" (p. 86) y las muchas horas que se pierden en la iglesia ("donde [la mujer] mora todo el santo día" -p. 85), o el condenable "misticismo que ciega y embrutece" (p. 242), que es resultado de la ignorancia en que los curas mantienen a las devotas, hasta los malos sacerdotes ("mercaderes del templo" -p. 209) o los peligros de la confesión y el celibato.

Estos dos últimos aspectos, la confesión y el celibato, son los que más reiteradamente aparecen en Indole. La opinión de Clorinda Matto sobre el celibato ya está claramente expuesta en Aves sin nido y en Indole no se hace más que reiterarla. La malsana pasión del cura Peñas por Eulalia y su desarreglada vida con Josefa (vid. II,.III) se explican en gran parte como resultado del celibato. A este respecto se lee lo siguiente:

¿Qué puede hacer el hombre de forzada continencia, cuando cae la paloma sin alas, falta de razón, con grilletes en la voluntad? ¡Devorarla! (p. 213).

Pero es la confesión el tema que recibe mayor atención en Indole. A lo largo de todo el relato el lector escucha incontables advertencias sobre los peligros de este sacramento; de manera especial, y con gran crudeza, sobre los peligros que encierra para la mujer y para la felicidad de la familia. Doña Asunción es un ser totalmente entregado - a la voluntad de su confesor y por eso mismo desgraciada en su matrimonio, mientras que doña Eulalia es sometida por el mismo confesor a un asedio sexual que también traerá dolor y sufrimiento a su familia. Incluso la inocente Ziska tiene que soportar también las indiscreciones del cura Peñas. De esta manera la confesión en Indole aparece siempre como una ocasión de pecado: 
iQuién había de decirle entonces que las flores y perfumes, símbolo de la virtud y de la santidad-del verdadero sacerdote, evaporándose poco a poco con el terrible ventarrón de la carne, se trocarían ora en gotas de veneno, ora en sierpes ponzoñosas para el hogar, excitadas en su apetito por aquella comunicación íntima, sin velo, sin reserva, del confesionario, donde la mujer iba a desnudarse moralmente todos los días! Acaso el mismo señor Peñas no fue responsable al iniciarse en la lid desigual para la mujer, con todas las ventajas de parte de quien dispone del sigilo y del supremo poder sobre la conciencia (pp. 212-213).

Esta visión de la confesión explica la insistencia con que aparece en la novela la frase "nadie entre los dos", como condición necesaria para la felicidad conyugal y en referencia explícita a la intromisión de los sacerdotes, vía el sacramento de la penitencia, en las relaciones de la pareja (vid. pp. 66, 92, 106, etc.). Indole no menciona para nada las bases teológicas del sacramento de la penitencia y se limita a mostrar sus inconvenientes sociales y morales. Si bien es cierto que de esta manera salvaguarda un cierto respeto a los principios nucleares del cristianismo, al mismo tiempo, al eludirlos por completo y contraponer su práctica a los intereses de la moral social, prefiriendo los mandatos de ésta, Clorinda Matto de Turner configura una posición crítica de notable fortaleza. De hecho pone en primer lugar el imperativo moral y la idea profana de bien social, dejando en un oscuro trasfondo toda reflexión propiamente religiosa, con lo que está mostrando una axiología laica como superior a otra de raíz religiosa.

Lo dicho hasta aquí indica que Indole construye, ahora en el plano del mensaje, una nueva oposición. De una parte se encuentra la afirmación vehemente délosiencumbrados valores religiosos; de otra, la irrealización personal y social de éstos, o inclusive su perversión. En el nivel de la representación concreta se prefiere el segundo lado, de suerte que en última instancia queda' en pie una imagen verdaderamente deplorable de la vida religiosa como realización social. En este sentido no es casual que el cura Peñas, cuya infamia se enfatiza a lo largo de todo el relato, termine triunfante (como en Aves sin nido sucedía con el cura Miranda) en un alto cargo eclesiástico: "señalado como personaje de campanillas, aclamado como patricio ejemplar y como varón santo que allá, en su curato, edificaba a su feligresía" (p. 249). Desde esta perspectiva es claro que en la novela se diseña un sentido fuertemente anticlerical (pues el buen sacerdote es una posibilidad jamás realizada en el texto) que en algunos momentos se acerca a la irreligiosidad propia del positivismo. Es significativo este abismo entre los ideales aceptados y su negación constante en el plano de la realidad representada: puede ser resultado de una inseguridad personal, como parte de la contradicción global que señala toda la obra de Clorinda Matto, o puede ser, también, no más que una suer- 
te de estrategia para burlar las presiones de una sociedad fanatizada, pero, en cualquier caso, es sugestivo observar cómo la realidad sigue siendo incapaz de variarlos a priori de la narración. Si en Aves sin nido el problema indígena no logra ser visto en sus dimensiones económicas más concretas, pese a la evidencia de éstas, en Indole el problema religioso tampoco se enfrenta en sus raíces y se prefiere, más bien, una opción moral que de alguna manera se escuda en el mal sacerdote y en la falsa religiosidad. Aún así, con todas estas limitaciones, Indole es una de las novelas que con más valentía ataca la cuestión religiosa. Como ya se ha visto, la pérdida de vigor en la crítica - social del mundo andino, que es el déficit más grande de esta novela, se compensa en cierta forma con la violencia que adopta, aun teniendo en cuenta sus límites, la crítica religiosa (10).

No está demás recordar que el argumento central de Indole, la pasión sexual del confesor por su penitente, repite en sus lineamientos generales el acontecimiento de El padre Horán (1848), del también cusqueño Narciso Aréstegui (11), y que tal vez ambas se alimentan del mismo episodio histórico (12). La comparación de la novela de Aréstegui con la de Clorinda Matto, sirve también para hacer más visible el mayor rigor y profundidad de la crítica que propone Indole (13). En ésta es visible la huella del pensamiento de González Prada (14).

\section{Las varias acepciones de la palabra "indole"}

A más de probar las inconveniencias de la confesión, Indole está destinada también a reflexionar narrativamente sobre el concepto de la palabra que le sirve de título; ol más concretamente, si se quiere, a demostrar que la "buena índole" termina siempre por imponerse sobre toda adversidad y sobre toda tentación que pretenda desviarla de su dirección originaria. Argumentalmente el imperio de la "buena ín-

(10) La crítica religiosa abarca también la intromisión de la política en la vida eclesiástica y la injusticia con que se distribuyen los altos cargos de la Iglesia.

(11) La novela de Aréstegui debió influir considerablemente en la Matto. La vigencia de esta influencia, ya visible en Aves sin nido, es notable en Indole.

(12) Algunos documentos relativos a este hecho, el asesinato por su confesor de Angela Barreda, han sido publicados por la Universidad del Cusco. Una más amplia referencia en el libro de Carrillo citado en la nota 3 , p. 28 , nota.

(13) En El padre Horán hay el cuidado de contraponer a la figura del sacerdote vicioso la del sacerdote santo y en ningún momento queda comprometida la jerarquía eclesiástica.

(14) Cf. Hugo Garcia Salvattecci: El pensamiento de Gonzales Prada, Lima Arica, 1972, I Part. 
dole" queda encomendado a la familia López: don Antonio y doña Eulalia serán los protagonistas de los distintos episodios que prueben la persistencia de esa disposición natural frente a los conflictos que va presentando la vida en sociedad.

La novela, sin embargo, demuestra una curiosa inseguridad en la conceptualización de este tema central. De hecho el relato incide varias veces en el sentido que corresponde a la palabra "índole", pero en todos los casos se observa la misma inseguridad y. en algunos más de una contradicción. Las contradicciones se hacen más obvias cuando el tema de la "índole" se pone en relación con otras reflexiones que también incorpora la novela, como Jas relativas a la Providencia o al determinismo material del comportamiento humano, por ejemplo.

Para Clorinda Matto "índole" es la fuerza ética que preside el comportamiento humano. Aunque en una primera oportunidad ofrece a este respecto una interpretación propia de los "moralistas" y de los "fatalistas" ("índole, eso que los moralistas llaman inclinaciones y los fatalistas califican de predestinación") y señala que "solamente ella" permite al hombre superar las "situaciones dolorosas" (p. 97), en un segundo momento, cuando la vigencia de la "buena índole" ha sido ya demostrada por el argumento (vid. pp. 132, 194), ensaya una interpretación científica que, sin embargo, coincide hasta literalmente con la versión moralista:

La ciencia humana, en sus relaciones fisiológicas, ha escrito también índole, traduciendo la tendencia o inclinación natural, peculiar a cada individuo (pp. 236-237, subrayado en el original).

En esta misma ocasión se establece que la "índole prevalece con mayor fuerza en la mujer" debido a que su deficiente educación la deja librada a sus "propias fuerzas" (p. 237). De esta manera parecería afirmarse que la "iriclinación natural" de cada quien puede ser materia de transformación por medio de la educación - con lo que comienza a pulsarse el tema central de Herencia, la tercera y última novela de la Matto (15). Esta posibilidad de transformación por la vía educativa es negada poco después, sin embargo, cuando se establece tajantemente que la "forma [de la concavidad cerebral] determina, ante la ciencia fisiológica, los talentos humanos y hasta la índole de los individuos" (p. 245).

Es claro que este crudo fisiologismo no sólo contradice la fe en la

(15) Clorinda Matto de Turner: Herencia (Noveld Peruana). Lima Matto Hnos., 1895. Aunque mucho más clara la filiación naturalista de esta novela, en ella el concepto de "herencia" tiene un tratamiento tan confuso como el de "índole" en la novela anterior. Con respecto a este tema puede verse mi "Prólogo" a la reedición de Herencia: Lima, Instituto Nacional de Cultura, 1974. 
educación y las contínuas alusiones a la Providencia (vid. p. 214); supone, globalmente, una alternativa científica que nada tiene que ver con los distintos conceptos, más bien idealistas, que la novela pone en juego. Es cierto que en algunos casos se trata de obviar la contradicción, como cuando se señala que los actos humanos no pueden cambiar la lógica de las leyes de la naturaleza en la medida en que "son leyes escritas por Dios" (p. 213), pero, en todo caso, es claramente perceptible una ambigüedad radical en la visión del mundo que subyace en Indole, ambigüedad que delata la presencia de elementos conceptuales de muy variada procedencia. Básicamente son factores idealistas, de filiación romántica, los que contienden con factores positivistas, de filiación naturalista, en el espacio de la segunda novela de Clorinda Matto. Por lo demás, el positivismo de Clorinda Matto nunca fue riguroso ni coherente, como tampoco lo fue el positivismo peruano, y siempre estuvo impregnado de rezagos idealistas. El tratamiento del concepto de "índole" es buena prueba de esto (16).

Naturalmente la ambigüedad conceptual tiene manifestaciones muy claras en el nivel de formalización del relato. De aquí que el lector pueda comprobar un claro desajuste entre ciertos fragmentos procesados bajo un modelo romántico, inclusive exacerbado, como el siguiente:

Encendiéronse sus mejillas con el tinte del granado, en sus pestañas tembló un gota de rocío que pronto cayó como un diamante cuajado para brillar sobre el pavimento, evaporándose después hacia la región de los misterios, y sus labios, acercándose el uno al otro cual dos rosas tquésel besan, murmuraron a media voz: Amén (p. 59),

$\mathrm{y}$ otros fragmentos que acuden, sin mayor eficiencia, al modelo naturalista: "sintió una oleada de oxígeno en sus venas" (pág. 60); "despertado en sus sentidos por el fluido magnético que le comunicaba aquella cintura oprimida por su brazo" (p. 70); "en sus ojos se había impreso más el círculo ojerozo, negro, que los rodeaba [ ...] que para el observador podía decir más que un libro de fisiología conparada" (p. 128), etc., etc. Estas indecisiones, que a veces llegan a constituirse como contradicciones flagrantes, son las que definen con mayor precisión la novelística de Clorinda de Matto en relación con las tensiones culturales de su tiempo (17).

(16) Sobre el positivismo en el Perú cf.: Augusto Salazar Bondy: Historia de las ideas en el Perú contemporáneo, Lima, Moncloa Editores, 1965, tm. I. Aquí se explican las limitaciones del positivismo nacional, limitaciones que expresa también nuestra novela realista.

(17) Cf. nota 1. 


\section{La función crítica dé la novela}

$\mathrm{La}$ intención crítica de Indole es manifiesta. Si bien aminora la dureza de sus juicios sobre la vida andina, aumenta - y muy considerablemente - su rigor con respecto a los problemas religiosos. Circundando ambos núcleos, Inclole desliza una serie de comentarios sobre la vida nacional y en ellos se aprecia, casi sin excepción, un tono claramente negativo.

Así, por ejemplo, a propósito del sangriento conflicto entre Castilla y Vivanco, cuya mención explícita fija en 1858 el tiempo del acontecimiento narrado (18), se alude a las "tantas luchas civiles en que dos caudillos disputan el poder" y a los grandes males que de ellas derivan (p. 215). La preeminencia del aspecto político en la vida nacional ("a todo se llega en el Perú por los tejidos de la política" -p. 265 ) es el resultado de esas perturbaciones sociales, que tampoco son ajenas, obviamente, al peligroso encumbramiento y extensión del poder militar: "en el país hasta las cosas del alma penden de nuestras bayonetas", dice con orgullo un oficial castillista (p. 235). Las fluctuaciones de la vida política impiden un desarrollo sostenido del país y fomentan, al menos indirectamente, el vicioso culto al éxito y a la exterioridad: en el Perú - se queja Clorinda Matto- los méritos sólo son reconocidos cuando se muestran "en la aparatosa forma de carruajes, sedas y lacayos" (p. 250) (19).

Frente a todos estos vicios, como también frente a los problemas de la falsa religiosidad, la novela tiene una función muy concreta. Amparada en los mandatos de la "moral social", la novela, la "novela trascendental", tiene que ljuzgar y condenar esa realidad deficitaria. Al hacerlo el novelistá se arriesga considerablemente: será vejado por los "pobres de espíritu". La reflexión sobre las funciones de la novela y los riesgos del novelista en el Perú está explícita en un largo inciso del capítulo $\mathrm{X}$ de la II Parte (20). Su texto completo es el que sigue:

(18) Se trata del ingreso a Arequipa de las tropas leales a Castilla. Este hecho sucedió en marzo de 1858, tras ocho meses de asedio. Cf. Jorge Basadre: Historia de la República del Perú, Lima, Ed. Universitaria, 1968, tm. V.

(19) Este tema será muy importante en Herencia. Antes lo habia tratado insistentemente Luis Benjamin Cisneros en sus dos novelas: Julia (1861) y Edgardo (1864).

(20) Hay otro párrafo que da una imagen totalmente distinta de la función de la novela: "eso dirán los novelistas, que inventan cuentos" (p. 58). Sin duda se trata de la opinión de un pensamiento que no es compartida por Clorinda Matto. Tal vez aluda a las novelas "puramente amorosas o recreativas" que condena en el "Proemio" de Aves sin nido. 
¿Quién podía fijarse en nimiedades en una sociedad donde se rinde culto al éxito, donde la virtud, que no descansa en la aparatosa forma de carruajes, sedas y lacayos, ni aun merece el nombre de tal? ¿Quién podía señalar a tipos como el que nos ocupa [el cura Peñas]?

Nadie sino el novelista observador que, llevando el correctivo en los puntos de su pluma, penetra los misterios de la vida, y descorre ante la multitud ese denso velo que cubre los ojos de los moradores ciegos y fanatizados a un mismo tiempo. El novelista de sana intención, llevado en alas de la moral social, en nombre de las mismas instituciones que deben depurarse a medida que el progreso se extiende.

En el Perú no existe, sin embargo, el temor del correctivo retocado por el romance, porque todavía la novela trascendental, la novela para el pueblo y para el hogar, no tiene ni prosélitos ni cultivadores. $\mathrm{Y}$ a juzgar por el grado de los adelantos morales, jay de aquella mano que, enristrando la poderosa arma del siglo, la tajante pluma, osara tasajear velo y tradición!

Los pueblos se moverían para condenarla en nombre del cielo prometido a los pobres de espíritu (pp. 250-251).

El texto anterior presagia la violenta reacción condenatoria que suscitaría Indole, como antes Aves sin nido, en razón básicamente de su enjuiciamiento della vida religiosa. $\Psi$ (es que Inalole, pese a todos sus defectos y limitaciones, pese a su ambigüiedad, atacó zonas muy sensibles del sistema ideológico de los grupos de poder más tradicionales, en especial de la Iglesia, y reafirmó de esta manera el sentido esencialmente crítico de la novelística de Clorinda Matto. Para ella la novela era sobre todo un instrumento de la moral social destinado a combatir los vicios de una sociedad que consideraba enferma y desviada. 